05,11

\title{
Намагниченность и гигантское магнетосопротивление поликристаллов TbSb при низких температурах
}

\author{
(C) М.П. Волков, Н.Н. Степанов \\ Физико-технический институт им. А.Ф. Иофрфе РАН, \\ Санкт-Петербург, Россия \\ E-mail: m.volkov@mail.ioffe.ru
}

Поступила в Редакцию 17 апреля 2019 г.

В окончательной редакции 17 апреля 2019 г.

Принята к публикации 17 апреля 2019 г.

На поликристаллах антимонида тербия $\mathrm{TbSb}$ проведены исследования зависимостей намагниченности $M$ и сопротивления $R$ от температуры $T$ в интервале $2-300 \mathrm{~K}$ и от магнитного поля $H$ до $H=14 \mathrm{~T}$. Установлено, при температурах ниже температуры перехода $\mathrm{TbSb}$ в антиферромагнитную фазу $\left(T_{\mathrm{N}}=14.8 \mathrm{~K}\right)$ на зависимостях $M(H)$ при каждой температуре наблюдается особенность (изгиб), связанный с метамагнитным фазовым переходом. Обнаружено гигантское положительное магнетосопротивление TbSb в области антиферромагнитной фазы.

Ключевые слова: антимонид тербия, намагниченность, магнетосопротивление, магнитные фазовые переходы.

DOI: 10.21883/FTT.2019.08.47971.457

Монопниктиды редких земель $R E-X$ (где $R E-\mathrm{Ln}$, a $X=\mathrm{N}, \mathrm{P}, \mathrm{As}, \mathrm{Sb}, \mathrm{Bi})$ образуют семейство бинарных соединений, кристаллизующихся в структурном типе $\mathrm{NaCl}$ и отличающихся широким разнообразием электрических и магнитных свойств: от металлических до полупроводниковых, от парамагнитных до антиферромагнитных [1-4]. Перспективы практического применения этих материалов связаны с возможностью направленной вариации большого числа параметров, таких как: катионанионный состав, концентрация свободных носителей тока, магнитные состояния. Одной из перспективных областей применения указанных материалов может, к примеру, оказаться разработка магнитных охладителей гелиевого диапазона температур [5].

Среди публикаций по исследованию магнитных, электрических и тепловых свойств монопниктидов лантаноидов известно всего несколько экспериментальных и теоретических работ, посвященных изучению моноантимонида тербия (TbSb) [6-10]. Было установлено, что антиферромагнитное упорядочение наблюдается в указанном соединении при понижении температуры ниже $T_{\mathrm{N}} \sim 15 \mathrm{~K}$ и сопровождается магнитострикционным эффектом - тригональным искажением его кристаллической структуры. В [10] сообщается также об особенности строения антиферромагнитной фазы в монокристаллах $\mathrm{TbSb}$ : магнитные моменты катионов упорядочиваются ферромагнитно в плоскости (111) и антиферромагнитно в прилегающих слоях с ориентацией вдоль направления $\langle 111\rangle$. В сильном магнитном поле возможно изменение магнитной структуры, что обусловлено квадрупольным эффектом взаимодействия магнитных моментов катионов [10]. Магнитные фазовые превращения могут проявляться и в процессах электропереноса $\mathrm{TbSb}$,
Однако до настоящего времени комплексное изучение магнитных свойств и коэффициентов электропереноса $\mathrm{TbSb}$ в широком диапазоне температур и в сильных магнитных полях не проводилось.

В данной работе представлены результаты измерений температурных и полевых зависимостей электросопротивления $(R)$ и намагниченности $(M)$ поликристаллического моноантимонида тербия (TbSb) в температурной области 2-300 К в магнитных полях до $14 \mathrm{~T}$.

Образцы для исследований представляли собой поликристаллы, которые приготовлялись методом сплавления элементов $(\mathrm{Tb}, \mathrm{Sb})$ в стехиометрической пропорции с последующим гомогенизирующим отжигом, аналогично процессу получения поли- и монокристаллов монохалькогенидов РЗЭ [11]. На первом этапе синтеза составлялась композиция из редкоземельного металла ( $\mathrm{Tb})$ в виде мелкой стружки (чистота $\geq 99.9 \%$ ) и пниктогена (в нашем случае $\mathrm{Sb}$ ) в виде тонкодисперсного порошка (чистота $\geq 99.99 \%$ ), которая загружалась в кварцевую ампулу. Откаченная до $10^{-7} \mathrm{MPa} \mathrm{и} \mathrm{запаянная} \mathrm{ампула}$ помещалась в специальную двузонную печь, в которой РЗМ выдерживается при более высокой температуре, чем пниктоген, но не выше $\approx 600^{\circ} \mathrm{C}$ и $\approx 450^{\circ} \mathrm{C}$ соответственно в течение $\sim 100 \mathrm{~h}$. Для полного завершения реакции синтезированный материал подвергался дополнительному отжигу при $\sim 800^{\circ} \mathrm{C}$ в молибденовом тигле в заполненной аргоном кварцевой ампуле с двойными стенками для предотвращения натекания воздуха через кварц в процессе нагрева. Вещество, полученное в результате синтеза, брикетировалось в пресс-формах при давлениях $\sim 1 \mathrm{GPa}$. Далее образцы подвергались гомогенизирующему отжигу при температуре $\sim 2000^{\circ} \mathrm{C}$ в заваренных молибденовых тиглях, помещенных в кварцевые 


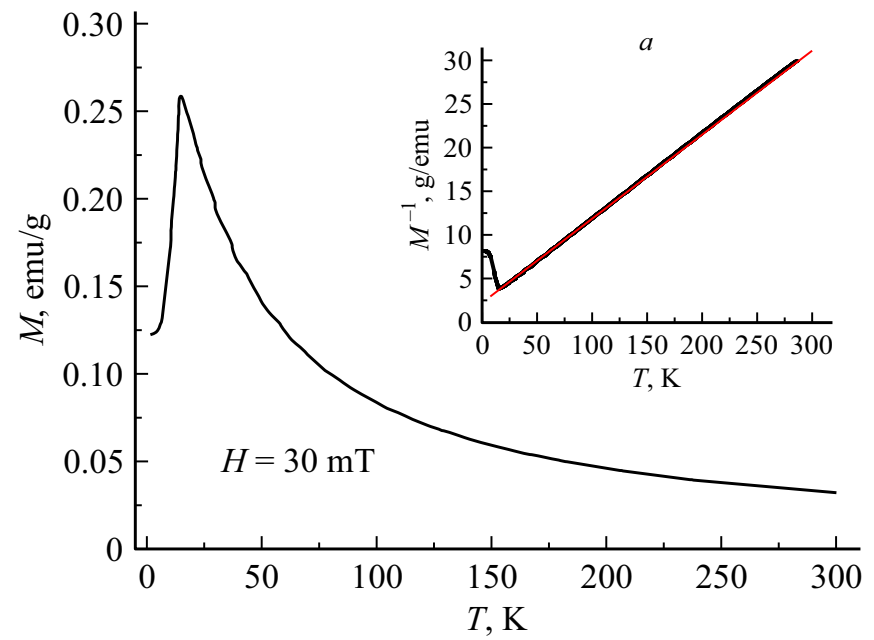

Рис. 1. Температурная зависимость намагниченности $M(H, T)$ поликристаллического антимонида тербия, $a-$ зависимость $M^{-1}(H, T) \mathrm{TbSb}$.

ампулы. На этом этапе синтеза получаются однородные по составу поликристаллические слитки $\mathrm{TbSb}$.

Рентгеноструктурный и рентгенофазовый анализы показали, что $\mathrm{TbSb}$ кристаллизуется в структурном типе $\mathrm{NaCl}$ и имеет постоянную решетки $a=6.17 \AA$. Иных фаз, кроме $\mathrm{TbSb}$, в исследуемом материале не обнаружено. Из полученных поликристаллов вырезались образцы для последующих измерения зависимостей электросопротивления и намагниченности от температуры $(2<T<300 \mathrm{~K})$ и магнитного поля $(H<14 \mathrm{~T})$. Зависимости намагниченности от температуры и магнитного поля измерялись на вибрационном магнитометре системы PPMS Quantum Design, измерение электросопротивления проводилось при токе $5 \mathrm{~mA}$ (ac mode).

На рис. 1 представлена температурная зависимость намагниченности $M$ поликристаллического образца TbSb. Магнитное поле напряженностью $30 \mathrm{mT}$ прикладывалось вдоль бо́льшего размера образца. Намагниченность $M$ возрастает при понижении температуры от комнатной $(300 \mathrm{~K})$ до $\approx 15 \mathrm{~K}$. На вставке рис. $1, a$ приведена зависимость $M^{-1}(T)$, которая в указанной температурной области строго линейна, подтверждая, тем самым, соблюдение закона Кюри-Вейса для $\mathrm{TbSb}$ в парамагнитной области. Максимум температурной зависимости намагниченности достигается в антимониде тербия при $T_{\mathrm{N}}=14.8 \mathrm{~K}$, которая и является температурой Нееля для данного соединения. Полученное значение $T_{\mathrm{N}}$ совпадает с таковым, приведенным ранее в [10]. При нескольких фиксированных температурах были измерены зависимости намагниченности $M$ поликристалла TbSb от магнитного поля $H$ (рис. 2, $a$ ), а на рис. $2, b$ представлены частные производные указанных зависимостей по магнитному полю $(\partial M / \partial H)$.

Из рис. 2, $a$ видно, что при $T<15 \mathrm{~K}$ функциональные зависимости $M(H, T)$ имеют вид кривых с перегибом, а на полевых зависимостях их производных $\partial M(H, T) / \partial H$ (см. рис. 2, $b)$ наблюдаются резкие максимумы, соответствующие точкам перегиба исходных функций $M(H, T)$. При температурах $2 \mathrm{~K}$ и $4 \mathrm{~K}$ зависимости $\partial M / \partial H$ практически совпадают, а при дальнейшем повышении температуры максимумы полевых производных $M$ или, другими словами, величина магнитного поля $H$, при котором наблюдается перегиб функции $M$, смещается в область малых полей и исчезает при переходе в парамагнитную область (см. рис. 3). На этом же рисунке представлена температурная зависимость магнитного поля $H_{\max }$, соответствующего точкам перегиба функции $M(H, T)$, полученная для монокристалла TbSb при ориентации $H$ вдоль направления $\langle 111\rangle[10]$, которое является направлением легкого намагничивания [12].

В температурной области $2-15 \mathrm{~K}$ с ростом напряженности магнитного поля в $\mathrm{TbSb}$ происходит магнитный фазовый переход (МФП) первого рода, связанный с перестройкой магнитной структуры соединения [10], что отражается на зависимостях $M(H)$ поли- и монокристаллов в виде изломов (перегибов) и можно ожидать,
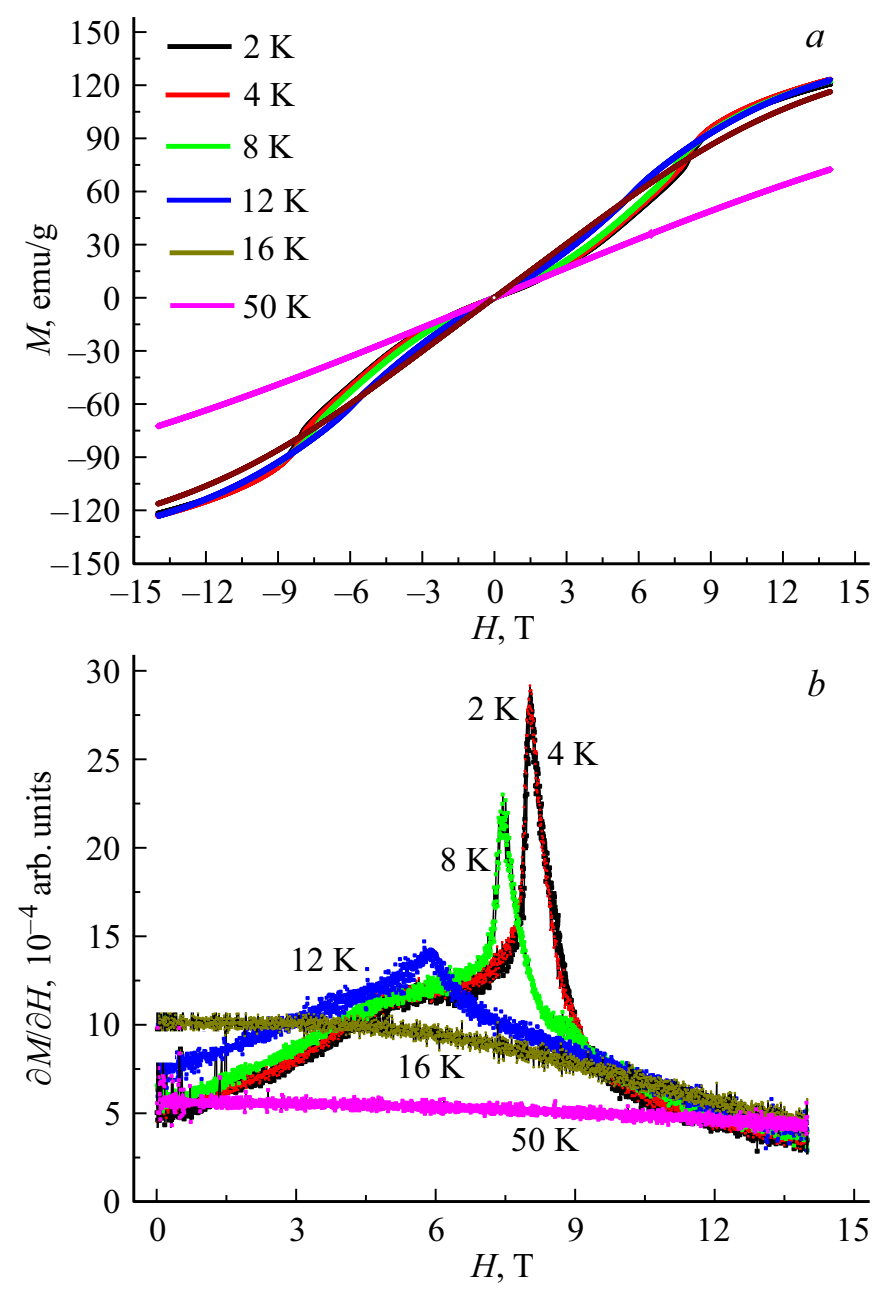

Рис. 2. Полевые зависимости удельного магнитного момента $\mathrm{TbSb}(a)$ и его производной по полю $(b)$ при различных температурах. 


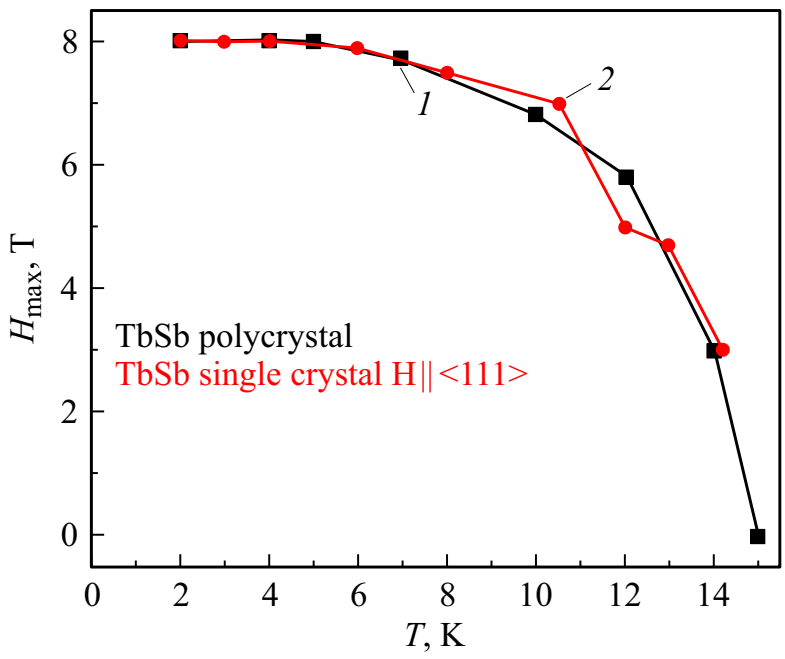

Рис. 3. Температурная зависимость магнитного поля $H_{\max }$, соответствующего точкам перегиба функции $M(H, T) 1-$ данные настоящей работы; 2 -- данные [10].

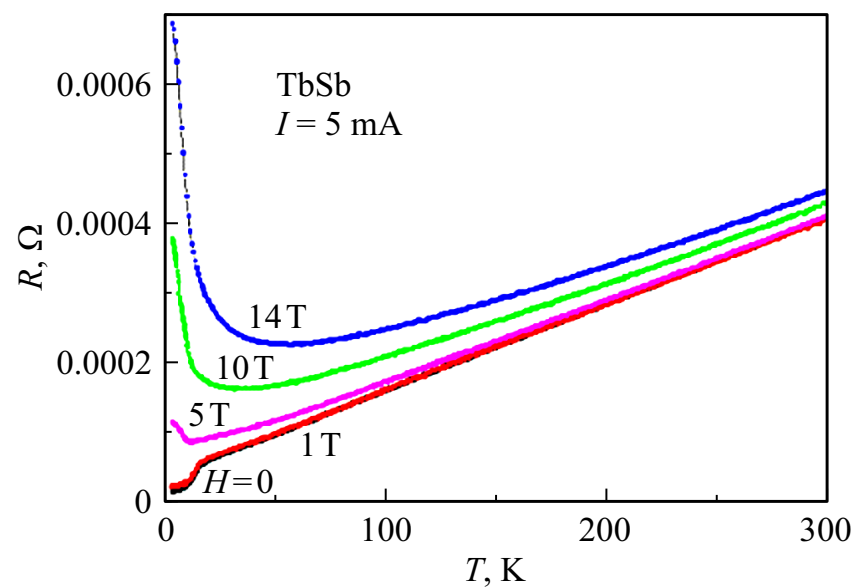

Рис. 4. Температурные зависимости электросопротивления $\mathrm{TbSb}$ в магнитных полях $H=0,1,5,10$ и $14 \mathrm{~T}$.

что наличие такого перехода будет наблюдаться и на зависимостях электросопротивления $R$ от магнитного поля.

Зависимости электросопротивления от температуры при фиксированных значениях магнитного поля, приложенного нормально направлению измерительного тока, представлены на рис. 4. Зависимость $R(T)$ при $H=0$ линейно убывает до $T \sim 15 \mathrm{~K}$, что характерно для металлического типа проводимости. При меньших температурах наблюдается резкое падение зависимости $R(T)$, обусловленное переходом $\mathrm{TbSb}$ в антиферромагнитное состояние, а затем величина $R$ далее практически не меняется, поскольку определяется остаточным электросопротивлением образца.

Во всем исследованном температурном интервале наблюдается большое магнетосопротивление $\mathrm{TbSb}$, наиболее отчетливо выраженное при низких температурах. При температуре $T=3 \mathrm{~K}$ электросопротивление $\mathrm{TbSb}$ в магнитном поле $14 \mathrm{~T}$ превосходит значение $R(H=0)$ в $\approx 45$ раз.

Полевые зависимости электросопротивления образцов $\mathrm{TbSb}$, полученные при различных температурах (представлены на рис. 5), достаточно хорошо описываются классической квадратичной функцией $R \sim H^{2}$, однако обнаруживают незначительные особенности в виде изломов, наблюдаемых на кривых $R(H, T)$ при $T=2 \mathrm{~K}$, $5 \mathrm{~K}$ и, в меньшей степени, при $10 \mathrm{~K}$. Более отчетливо отклонения от квадратичной зависимости электросопротивления антимонида тербия от индукции магнитного поля можно наблюдать, если построить графики частных производных $\partial R / \partial H \mathrm{TbSb}$ при различных температурах. Для трех температур $T=2 \mathrm{~K}, 5 \mathrm{~K}$ и $10 \mathrm{~K}$ такие графики приведены на рис. 6. На полевых зависимостях производных электросопротивления по полю $\partial R / \partial H$, представленных на рис. 6, присутствуют аномалии в виде отклонений от линейности, характеризующие наруше-

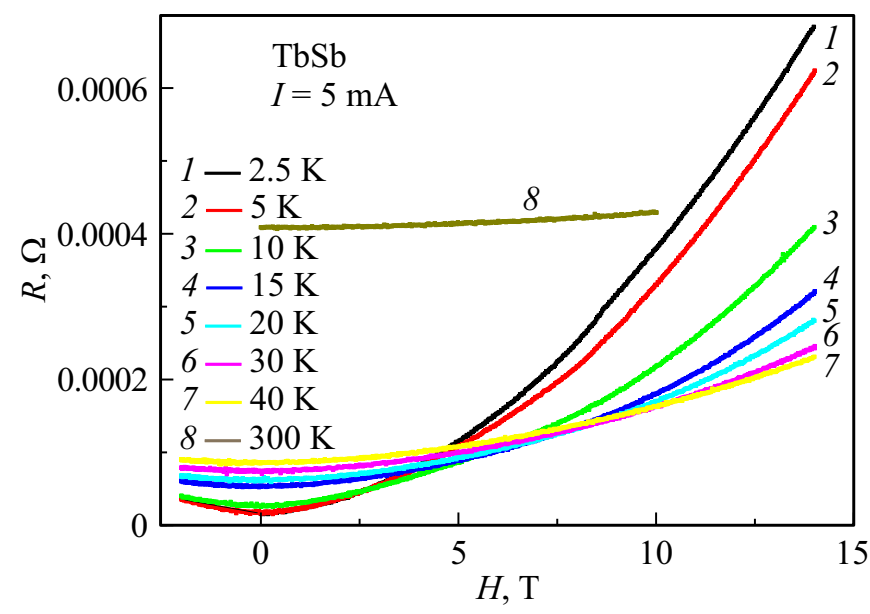

Рис. 5. Зависимости электросопротивления поликристаллического TbSb от магнитного поля при различных температурах.

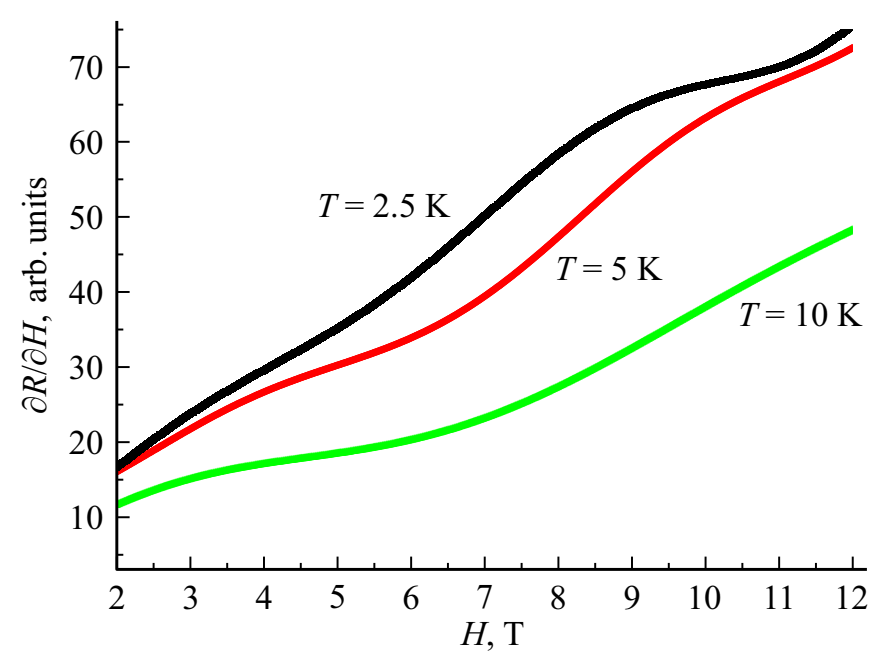

Рис. 6. Зависимости производных $\partial R / \partial H(a)$ поликристаллического образца $\mathrm{TbSb}$ от магнитного поля при температуpax $2.5 \mathrm{~K}, 5 \mathrm{~K}, 10 \mathrm{~K}$. 
ние квадратичного закона изменения функции $R(H, T)$. Можно предположить, что особенности $R(H)$ также связаны с магнитным фазовым переходом, приводящим к особенностям в $M(H)$. Так, для родственного соединения $\mathrm{NdSb}$ при измерениях на монокристаллах обнаружены небольшие скачки на зависимости $R(H)$, наблюдающиеся именно при полях магнитных фазовых переходов [13]. Для поликристаллических образцов $\mathrm{TbSb}$ особенности на зависимостях $R(H, T)$ сильно сглажены и не позволяют определить характерные поля с такой же точностью, как это возможно для зависимостей $M(H)$.

Таким образом, при исследовании зависимостей намагниченности $M$ и электросопротивления $R$ поликристаллического $\mathrm{TbSb}$ обнаружено, что при $T_{\mathrm{N}}=14.8 \mathrm{~K}$ материал переходит в антиферромагнитную фазу, при $T<T_{\mathrm{N}}$ на зависимостях $M(H)$ наблюдаются перегибы, соответствующие магнитному фазовому переходу. Значения магнитных полей этих особенностей совпадают со значениями полей магнитного перехода, наблюдавшегося ранее в [10] при ориентации магнитного поля вдоль оси $\langle 111\rangle$ монокристалла TbSb. Обнаружено гигантское положительное магнетосопротивление $\mathrm{TbSb}$ в области антиферромагнитной фазы, при этом на зависимостях $R(H)$ также наблюдаются сглаженные особенности.

\section{Конфликт интересов}

Авторы заявляют об отсутствии у них конфликта интересов.

\section{Список литературы}

[1] F. Hulliger. Rare Earth Pnictides. In: Handbook on the Physics and Chemistry of Rare Earths. / Eds. Karl A. Gschneidner, Jr. LeRoy Eyring. North-Holland, Amsterdam. (1979). V. 4. Ch. 33. P. 153.

[2] M.N. Abdusalyamova, O.R. Burmashev, K.E. Mironov. J. Less-Commun. Met. 77, 1, 81.

[3] Н.Н. Степанов, Н.В. Морозова, А.Е. Карькин, А.В. Голубков, В.В. Каминский. ФТТ 57, 12, 2300 (2015).

[4] F. Leuenberger, A. Parge, W. Felsch, K. Fauth, M. Hessler. Phys. Rev. B 72, 1, 014427-1 (2005).

[5] H. Nakane, S. Yamazaki, H. Fujishiro, T. Yamaguchi. Low Temperature Properties of HoSb, DySb. Cryocoolers 11 / Ed. R.G. Ross, Jr. Kluwer. Academic Plenum Publishers (2001) 443-448.

[6] T.M. Holden, E.C. Svensson, W.J.L. Buyers, O. Vogt. Phys. Rev. B 10, 9, 3864 (1974).

[7] P.J. von Ranke, P.O. Ribeiro, A. Magnus, G. Carvalho, B.P. Alho, T.S.T. Alvarenga, E.P. Nobrega, A. Caldas, V.S.R. de Sousa, P.H.O. Lopes, N.A. de Oliveira. J. Appl. Phys. 119, 18, 183903-1 (2016).

[8] Y. Nakanishi, T. Sakon, M. Motokawa, M. Ozawa, T. Suzuki. Phys. Rev. B 69, 2, 024412-1 (2004).

[9] A. Buschbeck, Ch. Chojnowski, J. Kötzler, R. Sonder, G. Thummes. JMMM 69, 2, 171 (1987).

[10] Y. Nakanishi, T. Sakon, M. Motokawa, M. Ozawa, T. Suzuki, M. Yoshizawa. Phys. Rev. B 68, 14, 144427-1 (2003).
[11] А.В. Голубков, В.М. Сергеева. Физика и химия редкоземельных полупроводников (Химия и технология). УНЦ АН СССР, Свердловск (1977) С. 28-35.

[12] T. Sakon, Y. Nakanishi, M. Ozawa, H. Nojiri, T. Suzuki, M. Monokawa. JMMM 177-181. Part 1. P. 355 (1998).

[13] Y. Zhou, X. Zhu, Sh. Huang, X. Chen, Y. Zhou, Ch. An, B. Zhang, Y. Yuan, Z. Xia, Ch. Gu, Z. Yang. Phys. Rev. B 96, 205122-1 (2017).

Редактор Т.Н. Василевская 